\title{
O fenômeno noticioso: objeto singular, natureza plural
}

Gislene Silva

\section{Resumo}

Do que é feita a matéria do Jornalismo? Mais precisamente, qual a natureza científica (episteme) do campo jornalístico e de seu objeto de estudo? Entre um extremo que supõe a inexistência de uma legitimidade teórica própria do campo jornalístico e outro que advoga uma ciência jornalística com autonomia teórica suficiente para dispensar até mesmo a transdisciplinaridade, proponho um caminho intermediário. Parto do princípio de que a Teoria do Jornalismo é um dos prolongamentos da Teoria da Comunicação e, concomitantemente, da hipótese de que é possível pensar cientificamente o fenômeno noticioso em sua especificidade. Este ensaio condensa, na primeira parte, minhas reflexões mais recentes sobre o campo epistêmico do jornalismo e a imaterialidade de seu objeto de estudo, para depois, na segunda parte, dar o passo seguinte: propor um conceito expandido de notícia, que tente superar o entendimento limitado de notícia como gênero (informativo), responda à particularidade do objeto de estudo do Jornalismo e, logo, contribua para sua teorização.

Palauras-chave:

Campo Jornalístico, Teoria do Jornalismo, Notícia, Epistemologia

Sobre a autora

Professora do Programa de Pós-

Graduação em

Jornalismo da

Universidade Federal de Santa Catarina

(UFSC).

Doutora em Ciências Sociais /Antropologia, pela PUC-SP. gislenedasilva@gmail.com

\section{The news phenomenon: singular object, plural nature}

\section{Abstract}

What is the substance of journalism made of? Precisely, what is the scientific nature (epistemic) of the journalistic field and his study object? Between on extreme position that supposes the nonexistence of theoretical legitimacy within the journalistic field and another that advocates a journalistic science whit theoretical autonomy, in that grade that it can allow to exempt even transdisciplinary approaches, I propose a middle way. Starting at the principle that the Journalistic Theory is an extension of the Communication Theory and, concomitantly, from the hypothesis that it is possible to think scientifically about the news phenomen, in his specificity. This essay condenses, in the first part, my recent reflections about the epistemic field of journalism and the immateriality of his study object, and then, in the second part, gives the next step: proposing an expanded concept of news, that tries to outgrow the limited understanding of news as genre (informative), answers the particularity of the study object of Journalism and, further, contributes for his theorizing.

Keywords:

Journalistic Field, Journalism Theory, News, Epistemology 


\section{Introdução}

Faz tempo assombra vários de nós estudiosos do jornalismo uma pergunta fantasma que, como um espírito errante, ora nos espreita, ora nos encara: afinal, do que é feita a matéria do Jornalismo? Mais precisamente, qual a natureza científica (episteme) do campo jornalístico e qual seu objeto de estudo? As investigações que tratam do jornalismo costumam ancorar-se em disciplinas outras - nas Ciências Humanas e Sociais, que apreendem o fenômeno noticioso em sua configuração sociológica, política, histórica, econômica e cultural; nas Ciências da Linguagem, que tomam o jornalismo como gênero ou discurso; nos Estudos Literários voltados para relatos e narrativas jornalísticas; nas disciplinas que elegem como centralidade os aparatos tecnológicos de divulgação e seus conseqüentes desdobramentos. Dentro do próprio campo da Comunicação, as pesquisas se limitam às teorias da notícia, interessadas apenas numa abordagem empíricodescritiva do produto do exercício profissional. Entre um extremo que supõe a inexistência de razões que sustentem a legitimidade teórica própria do campo jornalístico e outro que advoga uma ciência jornalística ou "Jornalogia" com autonomia teórica suficiente para dispensar até mesmo a transdisciplinaridade, defendo uma via per mezzo.

Esse caminho intermediário parte do princípio de que as teorias do jornalismo são teorias comunicacionais; quero dizer, uma vez que o jornalismo é um fenômeno comunicacional, a Teoria do Jornalismo está incluída na Comunicação. Concomitantemente, parto de que é possível pensar cientificamente o fenômeno noticioso em sua especificidade. Esse caminho passa por três questõeschave: (a) o campo epistêmico do jornalismo não pode se restringir ao conceito de campo jornalístico quando entendido somente como campo profissional; (b) o objeto de estudo do jornalismo extrapola a materialidade de suas manifestações concretas, empíricas; (c) a Teoria do Jornalismo, portanto, não pode ser elaborada exclusivamente a partir de estudos de formatos, técnicas, rotinas produtivas e conteúdos divulgados.

Muito do que vou tratar neste ensaio e que tem como base essas questões-chave vem sendo motivo de minhas reflexões no último ano e está detalhadamente explicitado em três diferentes trabalhos, apresentados em congressos recentes ${ }^{1}$. Revisitarei de modo bastante condensado, na primeira parte, as ideias principais aí desenvolvidas com o propósito de seguir adiante nesse caminho e proporei, na segunda, um conceito expandido de notícia, que tente superar o entendimento limitado de notícia como gênero (informativo), responda à particularidade do objeto de estudo do Jornalismo e, logo, contribua para sua teorização.

${ }^{1}$ Teorias da notícia: impasses para a Teoria do Jornalismo, em co-autoria com Felipe Pontes, congresso da SBPJor, novembro de 2008, em São Bernardo do Campo, SP; Sobre a imaterialidade do objeto do Jornalismo, congresso Lusocom, abril de 2009, em Lisboa, Portugal; De que campo do jornalismo estamos falando?, encontro anual da Compós, junho de 2009, Belo Horizonte, MG. Nestes textos constam todas as referências aos autores e ideias que inspiram as reflexões deste ensaio. 


\section{A matéria do jornalismo: campo, teoria e objeto}

Campo epistêmico diz respeito a investimento conceitual, metodológico e teórico. Por isso, para se elaborar a epistemologia de uma pretendida ciência jornalística ou "Jornalogia" (a subárea da Ciência da Comunicação que estuda o fenômeno comunicacional noticioso) não basta tomar o conceito de campo jornalístico, de Pierre Bourdieu, para se afirmar que já temos um campo próprio de estudos em jornalismo. O campo social do jornalismo, recortado pela abordagem sociológica, atende às demandas da Sociologia, não aos vazios conceituais de uma Teoria do Jornalismo. Tampouco resolve combinar este conceito de campo jornalístico com o de campo científico, também de Bourdieu. Ambos são variações de campos sociais, assim como o artístico, o econômico etc. É preciso separar o campo epistêmico do jornalismo (sua produção científica propriamente dita) do campo científicoinstitucional, muito fortalecido nos últimos anos no país com a criação da SBPJor (Associação Brasileira de Pesquisadores em Jornalismo), de revistas acadêmicas ou de linhas e núcleos de pesquisa específicos desta área e programas de pós-graduação especializados em jornalismo. Não estou negando, de modo algum, a imbricação entre a institucionalização político-acadêmica (programas, publicações, associações, congressos, fomentos etc) e a produção cognoscitiva (conceitos, métodos, teorias). Sabemos que fatores sociopolíticos, em diferentes escalas, influenciam os saberes que postulamos como válidos. Porém, reitero, acrescenta pouco ao aperfeiçoamento da Teoria do Jornalismo, de sua epistemologia própria, proclamar insistentemente a consolidação institucional do campo científico. Conquistar território acadêmico não é o mesmo que ganhar alcance teórico. A constituição do campo intelectual deve, ou deveria, basear sua legitimação mais nas competências teóricas do que nas institucionais. Ambas necessárias, mas não suficientes por si mesmas. Isso significa que é preciso investimento no capital cognitivo tanto quanto no capital político institucional.

Do mesmo modo, ao utilizar o conceito de campo jornalístico, é preciso não confundir campo profissional com campo teórico. $\mathrm{O}$ trabalho epistêmico exige a ruptura com o espontaneísmo. Por isso, repito, se trabalhar como jornalista demanda pensar contra os fatos, para ir do senso comum ao crítico - conforme propõe Sylvia Moretzsohn -, atuar na pesquisa em jornalismo requer eventualmente combater em si próprio o jornalista profissional, imerso na prática; obriga evitar a apologia da profissão nos empreendimentos epistemológicos. O problema é que a prática profissional, materializada em suas técnicas, processos e produtos, tem sido eleita como locus único de onde surgem espontaneamente as teorias do jornalismo. Com isso, as investigações deri-
Conquistar

território acadêmico

não é o mesmo

que ganhar

alcance teórico.

A constituição do campo intelectual deve, ou deveria, basear sua legitimação mais nas competências teóricas do que nas institucionais 
vadas dessa opção metodológica confinam o objeto de estudo do Jornalismo exclusivamente no seu produto material, no caso o jornal, a revista, o telejornal, o radiojornal e os sítios de notícias. A manifestação empírica do objeto ocupa, então, o lugar do próprio objeto de estudo e, por consequência, a Teoria do Jornalismo fica reduzida às teorias da notícia, aqui circunscritas às técnicas, processos e produtos da rotina profissional do jornalista. E quando o olhar restringe-se à expressão material de objetos específicos de pesquisa, não vai além de descrições. Tal empirismo descritivo impossibilita o afastamento necessário para enxergar o objeto de estudo do Jornalismo em sua real amplitude e, logo, teorizar mais amplamente. Essa visão também não favorece possíveis críticas ao fenômeno. Obviamente, a superação deste empirismo não invalida a necessidade dos estudos empíricos e aplicados para a elaboração de teorias, pois estas e aqueles formam o fluxo bidirecional para criar e sistematizar os conhecimentos sobre o fenômeno comunicacional noticioso.

\section{- conceito expandido de notícia}

A experiência jornalística que tem sido hegemonicamente considerada como fenômeno a ser pesquisado pela Teoria do Jornalismo diz respeito ao jornalismo tal qual conhecemos hoje, ou seja, dentro dos marcos de sua condição midiática, moderna, capitalista - um negócio que se sustenta em dispositivos tecnológicos em evolução, linguagens particulares, públicos diversos e requisitos técnicos, estéticos e éticos, sempre sujeitos às conformações históricas da sociedade industrial e urbana, democrática ou não. No entanto, se formos levar em conta que as diferentes manifestações jornalísticas se transformam historicamente e que o processo de comunicação social tanto se dá na manifestação comunicativa (interpessoal) como na comunicacional (mediada pela tecnologia), devemos considerar o fenômeno noticioso em suas múltiplas configurações. Seja quando mediado pela tecnologia da imprensa, rádio, tv, internet e multimídia, ou quando manifesto na forma manuscrita e mesmo na oralidade. Confirmaríamos, assim, o jornalismo como uma prática social eminentemente comunicativa e comunicacional, que agrega tecnicidade, perspectiva relacional, interação social, lugar de poder, política, produção econômica, circulação de discursos sociais, narrativa mítica, dimensão imaginária, troca simbólica e cultural etc. Em síntese, caso pretendamos chegar à natureza do fenômeno noticioso, devemos apreendê-lo em sua integralidade, como constituído e constituinte dos múltiplos aspectos da vida em sociedade.

A natureza plural do fenômeno noticioso, porém, não justifica o tratamento fragmentário do objeto de estudo de uma ciência jornalística. Não nos desobriga de investigar o centro de gravi-
Se formos levar em conta que as diferentes manifestações jornalísticas se transformam historicamente e que o processo de comunicação social tanto se dá na manifestação comunicativa

(interpessoal) como na comunicacional (mediada pela tecnologia),

devemos considerar o fenômeno noticioso em suas múltiplas configurações 
dade de uma possível questão geral, que poderíamos também nomear como núcleo objetivável, núcleo epistêmico ou mesmo como uma inteligibilidade, que consiga organizar conceitualmente a particularidade do fenômeno jornalístico. É por isso que a Teoria do Jornalismo deve ter como perspectiva própria explicar ou compreender um fenômeno social específico que se manifesta de incontáveis modos, desde os mais visíveis ou palpáveis (como os processos e produtos atraentes à observação empírica) até situações de comunicação jornalística impalpáveis, incorpóreas (como modos de recepção, lógicas de construção de sentido, ações de poder). Para tanto, teríamos de fazer a expansão do conceito de notícia e, logo, do próprio conceito de jornalismo, escapando daquele modelo hegemônico que tem conformado até agora a Teoria do Jornalismo (o de referência, de qualidade, informativo); de modo que caibam no núcleo epistêmico as mais diversas manifestações jornalísticas, sejam as emergentes na contemporaneidade, as clássicas da modernidade, as que antecedem os usos da tecnologia, as alternativas ao modelo empresarial-capitalista, as informais, as de baixa qualidade profissional, os múltiplos gêneros. A possibilidade de uma ciência jornalística, de uma Jornalogia, exige tomar a notícia como categoria central ou fundamento primeiro, considerando que o fenômeno noticia supera o gênero notícia, o típico do jornalismo informativo.

Com base no exposto até aqui, proponho um conceito expandido de notícia, que detenha a faculdade de transcender o entendimento limitado desta como gênero (informativo), de responder à particularidade do objeto de estudo do Jornalismo, sem sair do Campo da Comunicação, e de condizer com as características observáveis do jornalismo real, praticado no dia a dia. Considero que a ciência jornalistica tem como objeto de estudo o fenômeno notícia, e assim conceituo este fenômeno específico: notícia é a socialização de quaisquer informações de caráter público, atual e singular e que atendem a diferentes interesses. Com efeito, o jornalismo:

(1) transmite informações sobre qualquer assunto ou acontecimento: política, arte, ciência, entretenimento, economia, catástrofes etc, fazendo circular conhecimentos múltiplos.

(2) torna públicas as informações, faz saber a muitos.

(3) informa sobre temas e acontecimentos atuais, sejam do tempo presente ou do passado e que vieram à luz recentemente.

(4) para socializar informações, ele faz uso de linguagens, narrativas e simbologias (as estéticas de texto, imagem, som) e técnicas modelares.

(5) salienta do universo social vivido fenômenos singulares, ao mesmo tempo únicos e exemplares (ocorrências passíveis de observação ou questões manifestas à consciência),
Considero que a ciência jornalística tem como objeto de estudo 0 fenômeno notícia, e assim conceituo este fenômeno específico: notícia é a socialização de quaisquer informações de caráter público, atual e singular e que atendem a diferentes interesses 
(6) para transmitir utiliza diferentes aparatos, com tecnologias sofisticadas ou não.

(7) para socializar informações, exige trabalho e organização, sendo, portanto, uma mercadoria.

(8) ao selecionar informações, ele faz uso de seus próprios interesses.

(9) dirige informações a diferentes públicos, dada a heterogeneidade dos receptores, que por sua vez respondem por interesses também diversos.

(10) ao socializar informações colhidas na própria sociedade, ele mesmo é objeto de interesses externos (empresas, governo, pessoas comuns).

Temos, portanto, explícitos e inferidos nesta definição todos os elementos que dão forma à notícia, o objeto de estudo da Teoria do Jornalismo: informação, socialidade, poder, singularidade, atualidade, público, interesse, diversidade. Por lidar com informações quaisquer, o jornalismo abarca hardnews, softnews, fait-divers, matérias sensacionalistas, fofocas, dados científicos, banalidades, textos sérios ou engraçados, opinativos, literários, de substância verídica, verossímil ou mesmo falsa. Uma vez que o jornalismo trata declarações, temáticas e ocorrências concretas como fenômeno notícia, essa noção de notícia como objeto de estudo possibilita à Teoria um conceito mais complexo de acontecimento jornalístico, capaz de abranger desde os fatos mais verificáveis até abstrações diversas, como por exemplo, as da cobertura jornalística sobre arte. Ao socializar as informações fazendo uso de tecnologias e técnicas, a Teoria do fenômeno notícia aprecia as investigações sobre suportes e sobre formatos. Agrega também, ao viabilizar-se pelas linguagens, os estudos literários, estéticos, de narrativas, discursos e ideologias. Ao observar a atualidade como constituinte desse fenômeno, a Teoria também acolhe as pesquisas sobre diferentes temporalidades e periodicidades da experiência jornalística, o que demonstra que o conceito de notícia tem historicidade.

Quando elege a ação de tornar público uma característica essencial do fenômeno jornalístico, esta conceituação não só aponta para a necessidade social de notícia como incorpora os estudos sobre a relação informação-interesse. E isso é mais do que tratar do interesse público (importante, necessário) e do público (interessante, desejado). Diz dos interesses diversos de quem consome notícia como dos interesses de quem produz a mercadoria notícia (empresa, profissional, partido político, ONGs, sindicato, Estado) ou são sujeitos dela, como as próprias fontes ou os envolvidos. É aqui que se junta à Teoria o dever-ser do jornalismo, os estudos sobre a ética jornalística e o compromisso dessa prática profissional com a verdade. Esse dever-ser, embora fundamental
Temos, portanto, explícitos e inferidos nesta defínição todos

os elementos que dão forma à notícia, o objeto de estudo da Teoria do Jornalismo: informação, socialidade, poder, singularidade, atualidade,

público, interesse, diversidade 
para o exercício profissional, não tem garantia como característica intrínseca do fenômeno, já que o mau jornalismo é, como fenômeno, tão objeto de estudo da Teoria como o bom jornalismo. Jornais que, com freqüência, divulgam falsas notícias podem ser definidos como maus ou mesmo prejudiciais, dependendo da concepção utilizada de ética. Mas nem por isso seus conteúdos deixam de ser jornalísticos. Existe um continuum entre uma situação claramente antiética e uma idealmente ética, lembrando que esta possui historicidade e variabilidade e que, como nos lembram diferentes filosofias, depende do livre-arbítrio. No caso do jornalismo, nem sempre se cumpre o código deontológico. Por isto mesmo, a linha demarcatória entre um bom e um mau jornalismo é tênue e relativa. A fronteira entre notícia e propaganda, por sua vez, também é tênue e se rompe freqüentemente quando o jornalismo atua para atender interesses parciais, sejam ideológicos, políticos, religiosos ou comerciais.

Por fim, por cruzar conhecimentos diferentes e sistematizálos como fenômeno noticioso, a prática social do jornalismo pode ser pensada ela mesma como uma modalidade de conhecimento. Seja pela categoria da singularidade, com potência em si para o contextual do particular e do universal, como percebeu Adelmo Genro Filho, seja por outros modos de conhecer, como a arte literária, o senso comum ou o imaginário.

Concluo que o jornalismo, como um dos fenômenos sociais, tem uma especificidade que se presta à investigação científica, pela qual deve responder a Teoria do Jornalismo em consonância com a Teoria da Comunicação. Essa, a sua singularidade. Como a notícia é a socialização de quaisquer informações, ela abarca todo um mundo de conhecimento e, por isso mesmo, o estudo do fenômeno noticioso não deve dispensar os referenciais teóricos de ciências auxiliares, especialmente as Sociais e Humanas, tal como a Sociologia recorre à Economia, a Física à Matemática, a Biologia à Química. Essa, a sua pluralidade. Por todas essas razões deve-se abrir a Teoria do Jornalismo a partir da expansão do conceito de notícia. Um conceito reducionista de notícia, que não contempla a complexidade desse fenômeno no mundo, não só estreita o conhecimento como termina por falsificá-lo.

Recebido em 5 de outubro de 2009 Aprovado em 25 de outubro de 2009
Por cruzar conhecimentos diferentes e sistematizá-los como fenômeno noticioso, a prática social do jornalismo pode ser pensada ela mesma como uma modalidade de conhecimento 